\title{
Design of cam driving test equipment
}

\author{
Iryna Hren ${ }^{1, *}$, Petr Hejma ${ }^{1}$, Honza Svijantek ${ }^{1}$, and Josef Soukup ${ }^{1}$ \\ ${ }^{1}$ Faculty of Pruduction Technology and Management Jan Evangelista Purkyně University in Ústí nad \\ Labem, Department of Machines and Mechanics, 400 96, Pausterova 1, Ústí n/L, Czech Republic
}

\begin{abstract}
The work deals with the design of a test equipment designed for fatigue testing of the cutter bed. The disk cam drives the rocker, which is pressed against the cam surface by the coil spring. The test drum (buchar) copies the movement of the rocker to generate the exciting force that is loaded by the bed of the milling cutter. Based on unmatched data, the Wohler curve will be determined. This article deals only with parts of the design station. In particular, the design of the cam will be discussed here.
\end{abstract}

Keywords: cam, polynomial stroke, flat cam, torque.

\section{Introduction}

The presented proposal is part of an extensive research focusing on the dynamic characteristics of the cutter bed. In this paper, we only deal with the design of the cam profile. Based on geometric and kinematic relationships, we design a cam profile. The lender's track is prescribed by the project promoter, respectively, the kinematic quantities in place of the distance $a$ from the rotary connection (see Fig. 2). The aim of this paper is to design a profile whose rotation causes the builder to perform the prescribed movement. The following paragraphs describe the basic concepts of the cam mechanism.

The following figure (Fig. 1) schematically shows the configuration of the mechanism used for the design of the test device [1-3].

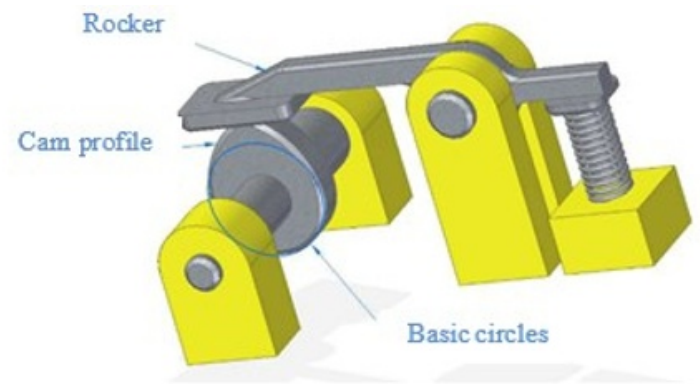

Fig. 1. The configuration of mechanism

The Fig. 1 shows the parts of the mechanism that will be referred to in the following text.

\footnotetext{
* Corresponding author: hren@,fvtm.ujep.cz

Reviewers: Darina Ondrušová, Konrad Waluś
} 
- Lever - a component of the cam mechanism transforming the rotary motion into a swinging motion

- Cam profile - functional area that is in contact with the hammer

- Basic circle - the smallest circle described by a point belonging to the cam profile

- Stroke dependency - function describing the position of the actuator depending on the angle of rotation of the cam.

\section{Designing a cam profile}

The cam is constructed as part of the mechanism which is designed to dynamically load the cutter bed [4-7]. The rocker that generates the test force $F_{b}$ is pressed by the coil spring onto the active surface of the cam. The operating conditions for the test mechanism are listed in the following table (Tab.1).

Table 1. Operating conditions for the test mechanism

\begin{tabular}{|c|c|l|l|}
\hline Designation & Units & Value & Description \\
\hline$o t$ & {$\left[\mathrm{~min}^{-1}\right]$} & 750 & camshaft speed \\
\hline$F_{\mathrm{b}}$ & {$[\mathrm{N}]$} & $3000 \quad$ to & range of exciting force \\
\hline$\Delta_{\mathrm{p}}$ & {$[\mathrm{mm}]$} & 5 & the initial compression of the spring \\
\hline
\end{tabular}

\subsection{Lifting phase}

The following figure is a kinematic diagram of the proposed mechanism [8-10]. In particular, the lift phase is indicated here. At a distance of [m] from the rotary link, the movement of the test roller with $[\mathrm{m}]$ is highlighted in red. $\varphi[\mathrm{rad}]$ is the angle of rotation of the cam. Calculation data was supplied by the contracting company. Specifically, the distances $a, c[\mathrm{~m}]$, the radius of the basic circle $R[\mathrm{~m}]$ and the stroke $s=s(\varphi)$. In addition, the cam rotates at a constant angular velocity, therefore $\varphi=\omega \cdot t$, where $\omega[\mathrm{rad} / \mathrm{s}]$ is the angular velocity and $t[\mathrm{~s}]$ is the time. $x[\mathrm{~m}], y[\mathrm{~m}], p[\mathrm{~m}], \zeta[\mathrm{rad}]$ and $y[\mathrm{rad}]$ indicate auxiliary dimensions important for the calculation $[11,12], \mathrm{w}[\mathrm{m}]$ is the segment defining the cam profile for a particular angle of rotation $\varphi$. 


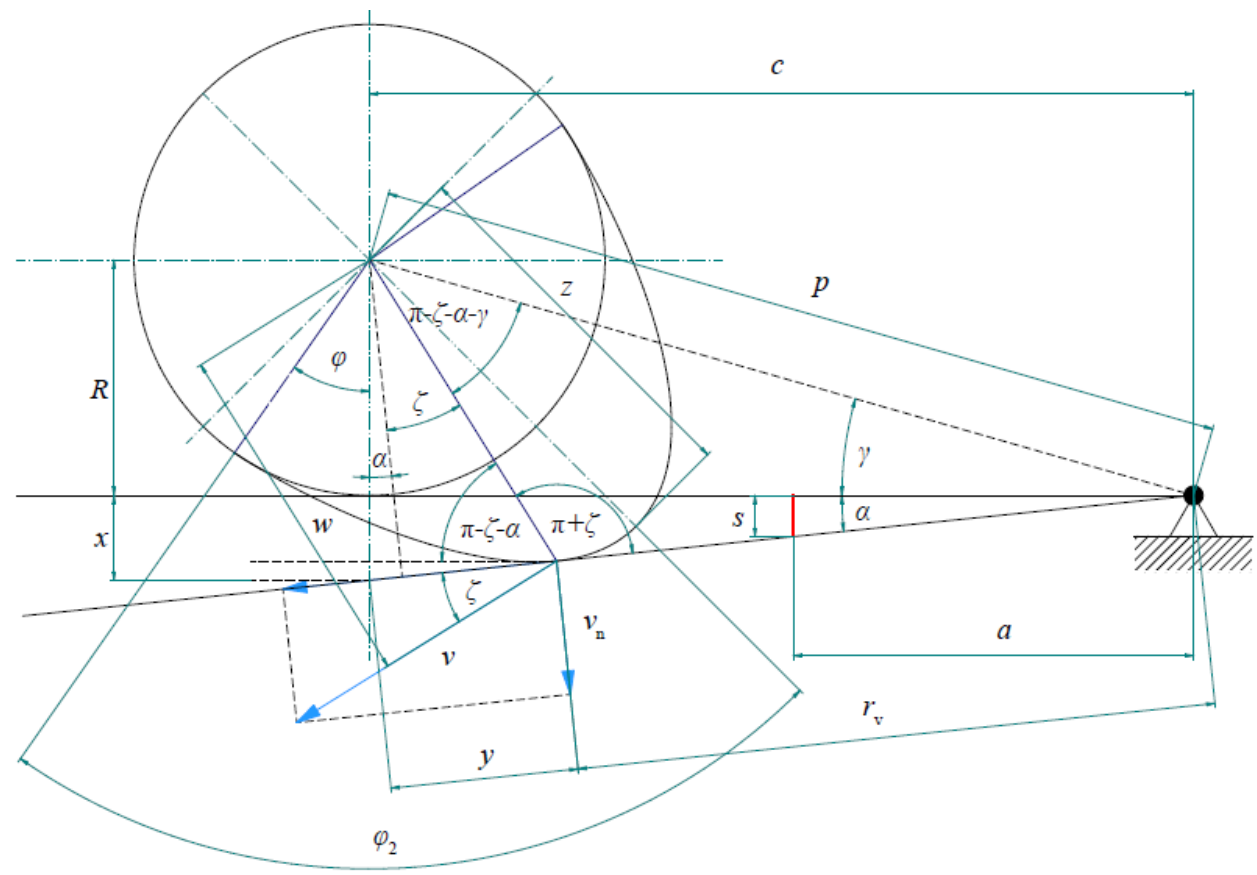

Fig. 2. Lifting phase

The rotation of the rocker a $[\mathrm{rad}]$ is given by the following relation.

$$
\alpha=\operatorname{arctg}\left(\frac{s}{a}\right) .
$$

For the cam rotating at the angular velocity $\omega$ the following relations apply.

$$
\begin{gathered}
v=w \cdot \omega \\
\sin (\zeta)=\frac{v_{\mathrm{n}}}{v} \rightarrow \quad v=\frac{v_{\mathrm{n}}}{\sin (\zeta)} \\
v_{\mathrm{n}}=\sin (\zeta) \cdot w \cdot \omega
\end{gathered}
$$

where: $v[\mathrm{~m} / \mathrm{s}]$ is the tangent velocity of the cam profile and $v_{n}[\mathrm{~m} / \mathrm{s}]$ is the tangent velocity.

There is a general kinematic binding between the weft and the cam (no rebound). Therefore, the following equations must apply to the balance.

$$
v_{\mathrm{n}}=r_{\mathrm{v}} \frac{\mathrm{d} \alpha}{\mathrm{d} t}
$$

Due to kinematic binding, equations (4) and (5) must be equal.

$$
\sin (\zeta) \cdot w \cdot \omega=r_{\mathrm{v}} \frac{\mathrm{d} \alpha}{\mathrm{d} t} \rightarrow w=\frac{r_{\mathrm{v}} \frac{\mathrm{d} \alpha}{\mathrm{d} t}}{\sin (\zeta) \cdot \omega} .
$$

The rotation derivative $\alpha$ (1) according to time corresponds to the angular velocity of the rocker. The speed of the rocker is adjusted by the following equation.

$$
\frac{\mathrm{d} \alpha}{\mathrm{d} t}=\frac{a}{a^{2}+s^{2}} \frac{\mathrm{d} s}{\mathrm{~d} \varphi} \frac{\mathrm{d} \varphi}{\mathrm{d} t} .
$$


Taking into account the constant angular speed of the cam rotation, the relation (7) can be given in the following form.

$$
\frac{\mathrm{d} \alpha}{\mathrm{d} t}=\frac{a}{a^{2}+s^{2}} \frac{\mathrm{d} s}{\mathrm{~d} \varphi} \omega
$$

By equating equation (8) into relation (6) equation (9) is created.

$$
w=\frac{r_{\mathrm{v}} \cdot a \frac{\mathrm{d} s}{\mathrm{~d} \varphi}}{\left(a^{2}+s^{2}\right) \sin (\zeta)} .
$$

Equation (9) expresses the cam profile and contains 3 unknown $w, r_{v}$ and $\zeta$. Therefore, the mathematical model of the mechanism needs to be supplemented by geometric relations.

$$
\begin{gathered}
\operatorname{tg}(\alpha)=\frac{x}{c} \rightarrow x=c \cdot \operatorname{tg}(\alpha), \\
\cos (\alpha)=\frac{c}{r_{v}+y} \rightarrow y=\frac{c}{\cos (\alpha)}-r_{v} .
\end{gathered}
$$

Next, we apply the cosine theorem to a triangle of sides of the lengths $w, y$ and $R+x$.

$$
w^{2}=(R+x)^{2}+y^{2}-2(R+x) y \cdot \cos \left(\frac{\pi}{2}-\alpha\right) .
$$

By establishing the relationships (10) and (11) into (12), equation (13) is created.

$$
w^{2}=(R+c \cdot \operatorname{tg}(\alpha))^{2}+\left(\frac{c}{\cos (\alpha)}-r_{v}\right)^{2}-2(R+c \cdot \operatorname{tg}(\alpha))\left(\frac{c}{\cos (\alpha)}-r_{v}\right) \cdot \sin (\alpha)
$$

Further, the relations of the triangle with the sides $r_{\mathrm{v}}, w$ a $p$ will be expressed.

$$
\begin{aligned}
& p=\sqrt{R^{2}+c^{2}}, \\
& \gamma=\operatorname{arctg}\left(\frac{R}{c}\right) .
\end{aligned}
$$

For this triangle, we can write Sine's sentence in the following form.

$$
\frac{p}{\sin \left(\frac{\pi}{2}+\zeta\right)}=\frac{r_{v}}{\sin \left(\frac{\pi}{2}-\zeta-\alpha-\gamma\right)}
$$

By using the goniometric relationships and expressing $r_{\mathrm{v}}$ we get a relationship (17).

$$
r_{v}=\frac{p \cdot \cos (\zeta+\alpha+\gamma)}{\cos (\zeta)}
$$

Relationships (17), (9) and (13) form a set of three equations of three unknowns. None of the unknowns can be expressed from the system, so the system will be solved numerically. The simple iteration method will gradually pass the angle of rotation $\varphi$ from zero to $\varphi_{2}$ after step $\Delta \varphi$, where $\varphi_{2}$ is the minimum angle required to reach the maximum stroke $z$ and $\Delta \varphi$ is the increment of angle. For each angle $\varphi$, the angle $\zeta$ will be stepped from 0 to the moment when the function $F$ (18) does not take the values below the defined limit $\varepsilon$. First, the value $r_{\mathrm{v}}(17)$ is calculated, then the value $w(9)$ is determinated. These values are then put into equation (18). 


$$
\begin{aligned}
F= & -w^{2}+(R+c \cdot \operatorname{tg}(\alpha))^{2}+\left(\frac{c}{\cos (\alpha)}-r_{\mathrm{v}}\right)^{2}- \\
& -2(R+c \cdot \operatorname{tg}(\alpha)) \cdot\left(\frac{c}{\cos (\alpha)}-r_{\mathrm{v}}\right) \cdot \sin (\alpha) .
\end{aligned}
$$

For a given angle of rotation of the cam, the auxiliary angle $\zeta$ from 0 to the time when the function $F(24)$ takes less than the defined limit $\varepsilon$ is again passed. The angle $\varphi$ of rotation of the cam is passed from $\varphi_{2}$ to the value $2 \varphi_{2}$.

\subsection{The return phase}

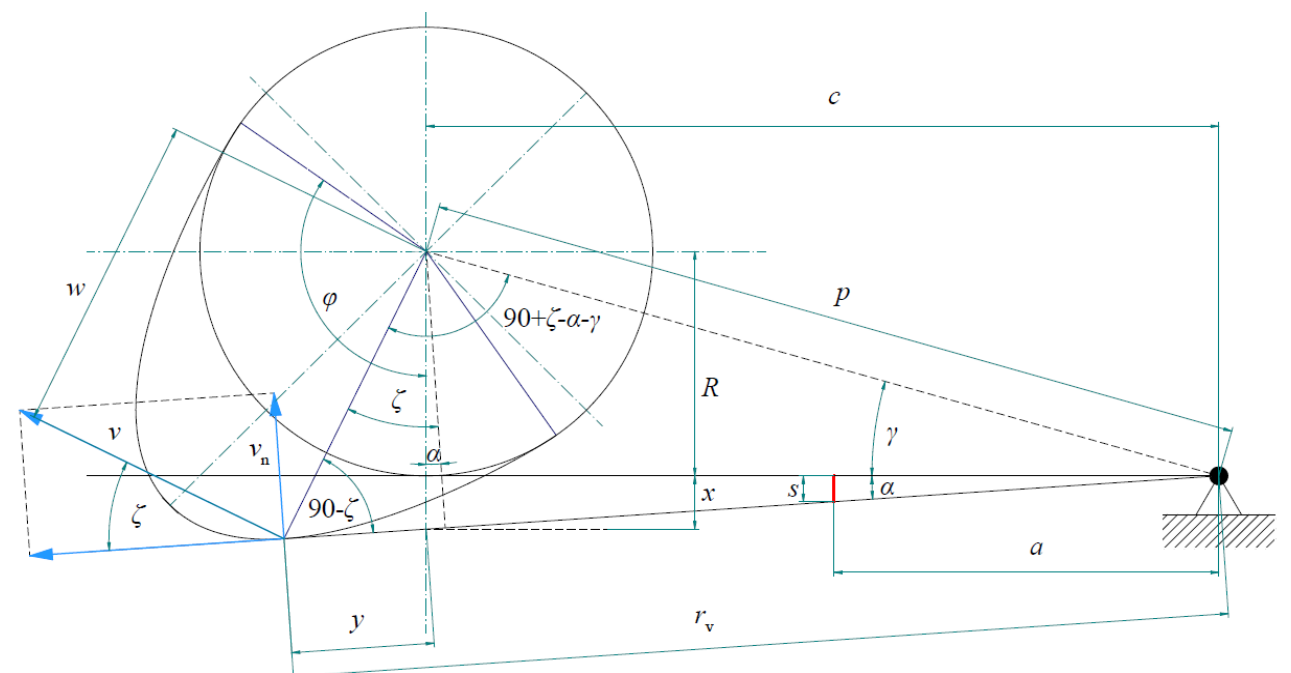

Fig. 3. Return phase

The return phase is bounded by the angle of rotation of $\varphi \in\left(\varphi_{2}, 2 \varphi_{2}\right)$. From the kinematics point of view, the equation (8) is equal to the stroke and return. From the point of view of the geometry of the mechanism, the relation (10) applies here as well. However, equation (11) must be modified as follows.

$$
\cos (\alpha)=\frac{c}{r_{v}-y} \rightarrow y=r_{v}-\frac{c}{\cos (\alpha)}
$$

As in the previous section, the cosine sentence for the triangle will be assembled on the sides $w, y$ and $R+x$.

$$
w^{2}=(R+x)^{2}+y^{2}-2(R+x) y \cdot \cos \left(\frac{\pi}{2}+\alpha\right) .
$$

By establishing the relations (10) and (19) into (20), equation (21) is created.

$$
w^{2}=(R+c \cdot \operatorname{tg}(\alpha))^{2}+\left(r_{v}-\frac{c}{\cos (\alpha)}\right)^{2}+2(R+c \cdot \operatorname{tg}(\alpha))\left(r_{v}-\frac{c}{\cos (\alpha)}\right) \cdot \sin (\alpha) .
$$

Equations (14) and (15) also apply to the return of the rocker. Analogously to equation (16), the triangle on the sides of $r_{\mathrm{v}}, w$ and $p$ will be given the Sine theorem.

$$
\frac{p}{\sin \left(\frac{\pi}{2}-\zeta\right)}=\frac{r_{v}}{\sin \left(\frac{\pi}{2}+\zeta-\alpha-\gamma\right)}
$$


Using the trigonometric formulas, we modify the equation (22) into the following shape.

$$
r_{v}=\frac{p \cdot \cos (\alpha+\gamma-\zeta)}{\cos (\zeta)}
$$

As in the previous section, we look for the numerical solution of the following equation.

$$
\begin{aligned}
F= & -w^{2}+(R+c \cdot \operatorname{tg}(\alpha))^{2}+\left(r_{v}-\frac{c}{\cos (\alpha)}\right)^{2}+ \\
& +2(R+c \cdot \operatorname{tg}(\alpha))\left(r_{v}-\frac{c}{\cos (\alpha)}\right) \cdot \sin (\alpha) .
\end{aligned}
$$

For a given angle of rotation of the cam, the auxiliary angle $\zeta$ from 0 to the time when the function $F$ (24) takes less than the defined limit $\varepsilon$ is again passed. The angle $\varphi$ of rotation of the cam is passed from $\varphi_{2}$ to the value $2 \varphi_{2}$.

\subsection{Solution}

The above calculation methodology will be applied in this part to the specific requirements that are placed on the mechanism. The following figure shows the desired position of the test roller depending on the angle of rotation of the cam.

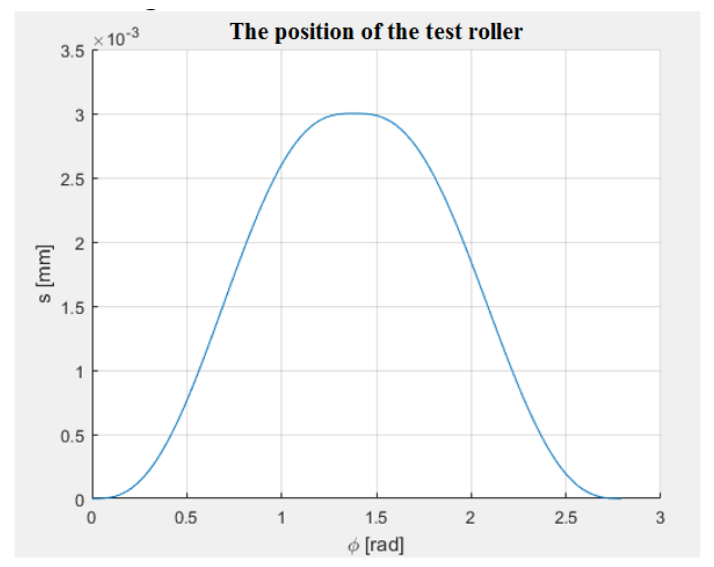

Fig. 4. Position of the test roller

The Cartesian coordinates of the cam profile are in the opposite way to the cam profile in polar coordinates. A rocker with a slope associated with the angle $\varphi_{i}$ is ,attached" to the fixed cam. The cam coordinate system is positioned so that the $z$ axis is the same as its axis of rotation, and the $y$-axis passes the most distant point of the cam profile from its axis of rotation (instead of the maximum stroke). By the numerical solution of equations (18) and (24), we obtain an $\zeta_{i}$ corresponding to the specific angle of rotation of $\varphi_{i}, \varphi_{i} \in\left\langle 0,2 \varphi_{2}\right\rangle$. This is denoted as $\zeta\left(\varphi_{i}\right)$. Based on $\zeta\left(\varphi_{i}\right)$ we calculate $r_{\mathrm{v} i}$, this denote $r_{\mathrm{v}}\left(\varphi_{i}\right)$ - equation (17) and (23). This is the shortest distance from the point of contact of the cam with the weft from the rotation axis of the cam depending on the angle of rotation $\varphi_{i}$. Based on this data, we calculate $w_{i}$ depending on $\varphi_{i}$. We denote $w\left(\varphi_{i}\right)$. The vectors $\zeta\left(\varphi_{i}\right), r_{\mathrm{v}}\left(\varphi_{i}\right)$ and $w\left(\varphi_{i}\right)$ are $2 n$ large. For the return phase, the following equation applies, where $i \in\langle 1, n-2\rangle$.

$$
x_{v i}=-w\left(\varphi_{2 n-i+1}\right) \cos \left(\frac{\pi}{2}+\varphi_{2}+\zeta_{2 n-i+1}-\alpha_{2 n-i+1}-\varphi_{2 n-i+1}\right),
$$




$$
y_{v}=w\left(\varphi_{2 n-i+1}\right) \sin \left(\frac{\pi}{2}+\varphi_{2}+\zeta_{2 n-i+1}-\alpha_{2 n-i+1}-\varphi_{2 n-i+1}\right) .
$$

For the return phase, the following equations apply, where: $i \in\langle n, 2 n\rangle$.

$$
\begin{aligned}
& x_{v i}=w\left(\varphi_{2 n-i+1}\right) \cos \left(\frac{\pi}{2}-\varphi_{2}+\zeta_{2 n-i+1}+\alpha_{2 n-i+1}+\varphi_{2 n-i+1}\right), \\
& y_{v i}=w\left(\varphi_{2 n-i+1}\right) \sin \left(\frac{\pi}{2}-\varphi_{2}+\zeta_{2 n-i+1}+\alpha_{2 n-i+1}+\varphi_{2 n-i+1}\right) .
\end{aligned}
$$

The enumeration of the individual parameters of the mechanism specified by the manufacturer follows.

Table 2. Mechanism parameters

\begin{tabular}{|c|l|l|l|}
\hline Designation & Units & Value & Description \\
\hline$a$ & {$[\mathrm{~mm}]$} & 200 & $\begin{array}{l}\text { the axis of rotation of the rocker from the axis of the test } \\
\text { roller }\end{array}$ \\
\hline$Z_{0}$ & {$[\mathrm{~mm}]$} & 3 & stroke of the test roller \\
\hline$R$ & {$[\mathrm{~mm}]$} & 40 & radius of the base circle of the cam \\
\hline$\varphi_{2}$ & {$[\mathrm{deg}]$} & 80 & the minimum stroke angle \\
\hline
\end{tabular}

The cam designed according to the above methodology has the following form.

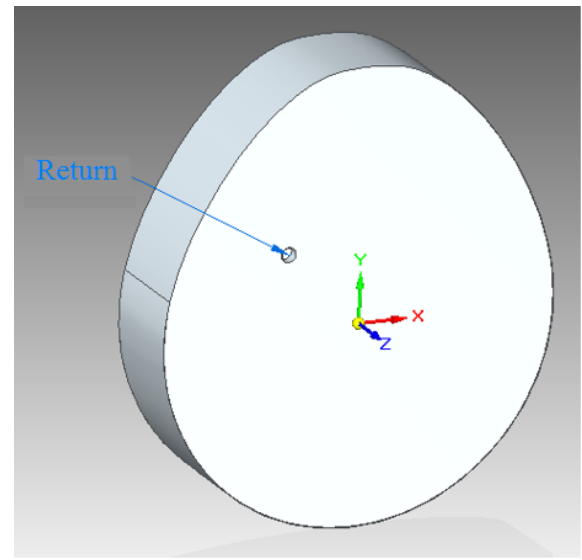

Fig. 5. Cam

\section{Conclusion}

The paper deals with the design of the cam for the test equipment, which serves for the dynamic stress of the milling bed. On the basis of geometric and kinematic contexts a set of three equations of three unknowns was compiled, which could not be solved analytically. So the system was solved numerically by the simple iteration method. The result is the cam profile coordinates. The cam was then modeled in Inventor software. By positioning the cam at a distance of $c=700 \mathrm{~mm}$ from the rotational coupling (see Fig. 2 and Fig. 3) and rotating $750 \mathrm{rpm}$, the stroke dependence is defined at a distance of $a=200 \mathrm{~mm}$ from the rotary coupling.

This contribution was created in support of project SG 4820715 2014-48 01 at UJEP. 


\section{References}

1. P. Hejma, F. Klimenda, J. Kampo, Návrh profilu vačky. Dynamika tuhých a deformovatelných těles (2015)

2. P. Hejma, M. Svoboda, J. Kampo, J. Soukup, Analytic analysis of a cam mechanism. In Procedia Engineering 177, 3-10 (2017)

3. R. G. Budynas, Shigley's Mechanical Engineering Design. 8th ed. in SI Units. The McGraw-Hill Companies. Inc. (2008)

4. M. Sapieta, P. Šulka, M. Svoboda. Localization of delamination in composite test specimen. MATEC Web of Conferences 157, 01015 (2018)

5. I. Blanco, V. Diaz, J., L., P. Cam design. Universidat Carlos III in Madrid. (2005)

6. M. Apetaur, F. Klimenda, Mechanika výrobních strojů. Manipulátory a průmyslové roboty. 1. vydání. 95 pp. (2014)

7. P. Lakshminarayanan, N.S. Nayak, Critical component wear in heavy duty engines. John Wiley \& Sons Singapore, 47- 66 (2011)

8. R. Křižík, K. Weigner, J. Svoboda, Stavba a provoz strojů III Mechanizmy. SNTLNakladatelství technické literatury. (1983)

9. H. A. Rothbart, Cam design handbook. The McGRAW-HILL Companies, Inc. 587 pp. (2004)

10. S. Borkowski, Toyotarity. Innovations. Improvement. Polski Instytut Jakości sp.z o.o. 190 pp. (2016)

11. J. Leinveber, J. Řasa, P. Vávra. Strojnické tabulky. Scientia, spol. s. r. o., Praha. (2002)

12. E. Ciulli, B. Piccigallo, D. Vela. Experimental study of engine camfollower. In Proceedings of the XIX Congresso AIMETA. Ancona. (2009) 